\title{
CONSTITUTIVISM WITHOUT NORMATIVE THRESHOLDS
}

\author{
Kathryn Lindeman
}

\author{
Even bad coffee is better than no coffee at all. \\ -David Lynch
}

\begin{abstract}
Constitutivists about noRms in metaethics explain the normative standards in a domain by appealing to constitutive features of the members of the domain. ${ }^{1}$ So, for example, Korsgaard seeks to explain what it is to be a good person by appeal to what it is to be a person. This is an appealing explanatory strategy because, if successful, it offers a general and comprehensive account of how different normative standards govern distinct normative domains. It could, e.g., explain how moral normative standards govern agents, practical normative standards govern purposive behavior, epistemic normative standards govern beliefs and inferences, artifactual normative standards govern artifacts, and biological normative standards govern organs and biological processes. ${ }^{2}$
\end{abstract}

1 Constitutivism is often presented, as with Enoch, as "a family of views that hope to ground normativity in norms, or standards, or motives, or aims that are constitutive of action and agency" ("Shmagency Revisited," 208). Or, by Tiffany, as "the view that it is possible to derive contentful, normatively binding demands of practical reason and morality from the constitutive features of agency" ("Why Be an Agent?" 223). I prefer a more ecumenical characterization in which the norms need not be those of practical reason and they need not be grounded in what is constitutive of action or agency, but rather can be grounded in any constitutive feature of the individual governed by the norms. An argument for this preference is beyond the scope of this paper, but this view is implicitly presupposed by the targets of my arguments. An even more inclusive characterization is defended by Michael Smith (in "A Constitutivist Theory of Reasons"), who characterizes any account that reduces a normative feature to a constitutive feature of some other thing.

2 Constitutivism is often contrasted with constructivism and realism. To understand these contrasts, it is important to specify the domain about which one is a constitutivist, realist, or constructivist. It is possible to be a constitutivist about one domain and an error theorist about another, for example, though it is not possible to be an error theorist and constitutivist about the same domain. I discuss constitutivism about norms. For a useful discussion of the relationship between constructivism and constitutivism, see Schafer, "Realism and Constructivism in Kantian Metaethics (1).” 
A central challenge for normative constitutivism is to account for the connection between an individual's constitutive nature and its normative standards. Critics worry that this kind of explanation is impossible. ${ }^{3}$ One prominent objection to constitutivism is the worry that normative standards governing an individual cannot be grounded in its kind in the way constitutivists claim without ruling out the possibility that kind-members could violate those standards. This objection is sometimes called the Problem of Bad Action. ${ }^{4}$

The main lesson of this paper is that current constitutivist accounts face a serious threat, though not from the well-known Problem of Bad Action. Rather, the way in which they take norms to constitute norm-governed kinds commits them to what I call the Threshold Commitment. This, I argue, leads to serious costs for constitutivists that should lead them to reject this commitment and seek another explanation of this connection.

\section{VIOLABILITY AND NAÏVE CONSTITUTIVISM}

One naïve constitutivist explanation of norms is that the norms themselves are constitutive of individuals in virtue of being satisfied. This account generates norms that are unable to account for what I call Violability.

Violability: That a norm applies to $x$ and requires $p$ does not logically or metaphysically imply that $x$ satisfies $p$.

Problematically, such explanations cannot be used to account for the obvious fact that there are better and worse things in the world. Railton raises a concern of this form when he worries how we could, e.g., determine whether someone who fails to aim at truth in forming beliefs is defective. He writes that "to dis-

3 In this paper, I focus on the criticism that the constitutive connection between norms and kinds causes insurmountable problems for constitutivists. Recently another criticism has become increasingly popular against constitutivism. David Enoch (see "Agency, Shmagency" and "Shmagency Revisited") and Kieran Setiya (see "Explaining Action" and Reasons without Rationalism) worry that the constitutive starting point is either too anemic to provide a full accounting of the normative landscape or too robust to be normatively uncontroversial. This objection is orthogonal to the problem I discuss in this piece, but I discuss it in "An Explanation of Constitutivist Normativity." For helpful discussions of the issues remaining for constitutivists in light of these objections, see Rosati, "Agents and 'Shmagents"; and Silverstein, "The Shmagency Question."

4 The problem of bad action is so called because it has been raised in response to constitutive accounts of practical norms. However, because the problem is supposed to arise from the form of constitutive explanation, not the nature of the practical domain, there will be analogous problems for all normative domains. The problem is, therefore, more general than the name lets on. 
cover that the metal in the sample tray on one's laboratory bench has atomic number 82 is not to discover that it is 'defective gold,' but rather that it is not gold at all. A similar problem confronts all constitutive arguments." Clark raises similar worries specific to Velleman: if any action must have the aim of autonomy, but autonomy is a precondition of action, all action necessarily achieves its aim. If constitutive accounts are the only explanation of the normative features of action (including reasons for action), any action that achieves its aim should, it seems, have no reasons that speak against it, making it incapable of being rationally criticized. ${ }^{6}$

Railton and Clark both highlight specific instances of a more general concern about the role this naive account gives to standards: if what it is to be a member of a norm-governed kind is to meet a certain standard, then that standard seems incapable of simultaneously serving as a way to differentiate good kind-members from bad kind-members. The naive view then is a nonstarter for constitutivists for exactly the reason Railton and Clark highlight. Any successful constitutivist explanation must provide a metaphysical account of the constitutive features of normatively evaluable kinds that is consistent with Violability. This account must show that there is some connection between the kind and the norms tight enough to account for the constitutive explanation, but weak enough to allow for defect and other evaluations according to norms. ${ }^{7}$

Constitutivists are clearly aware of the need for non-naïve constitutive explanations. Velleman, for example, recognizes the importance of distinguishing between the conditions on aiming and actually achieving an aim. He writes that "If autonomy were the constitutive aim of action, then every instance of action... would turn out to be a success." ${ }^{8}$ Korsgaard seems similarly interested in leaving room for norms to be constitutively understood while not satisfied. In the specific case of norms constitutive of action, she writes:

5 Railton, "On the Hypothetical and Non-Hypothetical in Reasoning about Belief and Action," 70.

6 Clark, "Velleman's Autonomism," 581-82. Clark quotes Velleman, The Possibility of Practical Reason, 185.

7 For worries of this nature by critics, see Railton, "On the Hypothetical and Non-Hypothetical in Reasoning about Belief and Action"; Clark, "Velleman's Autonomism”; Barandalla and Ridge, "Function and Self-Constitution"; Lavin, "Practical Reason and the Possibility of Error"; Silverstein, "Teleology and Normativity." For worries acknowledged by constitutivists, see the introduction in Velleman, The Possibility of Practical Reason; Korsgaard, Self-Constitution, especially sec. 8.1; and Katsafanas, Agency and the Foundations of Ethics, 61-63.

8 Velleman, The Possibility of Practical Reason, 3on37. Further discussion of Velleman's view can be found in section 6, below. 
[If] it is the essential nature of [a kind] that it have a certain metaphysical property ... but in order to have that metaphysical property it must have a certain normative property ... then this explains why the [individual] must meet the normative standard: it just isn't [a member of the kind] if it doesn't. But it also seems as if it explains it rather too well, for it seems to imply that only good [individuals] really [are kind-members], and that there is nothing left for bad [kind-members] to be. ${ }^{9}$

There are less naïve explanations of how normative standards are related to the constitutive features of kind-members that preserve Violability. Constitutivists might, for instance, take normative satisfaction to be a scalar matter, and claim that some degree of normative satisfaction is constitutive. So long as the metaphysical property can be realized by a number of normative properties, or by having some normative property to some degree, this connection need not rule out Violability. So, constitutivist accounts that permit scalar norm satisfaction as a criterion of kind-membership would be perfectly compatible with violated norms and defective kind-members. Indeed, such views seem to be held by many constitutivists. Korsgaard and Velleman, for example, hold that constituting oneself and aiming at agency are activities that agents can do in better and worse ways. Neither accounts for the relationship between individuals and kinds on the naïve model that would make them natural targets for Railton's objection.

So, for example, Korsgaard, in Self-Constitution, explains the constitutive feature uniting kinds as a matter of having an internal teleological organization or form, which is a matter of minimally satisfying some constitutive standards or norms. Though you must be in the practice of constituting yourself to be evaluated according to the constituting-oneself standards (i.e., practical norms), there are better and worse ways of doing this, and so better and worse agents. ${ }^{10}$ The norms of self-constitution are, therefore, scalar; there are ways of violating the norms and still being an agent, because you are still constituting yourself, just doing so badly. ${ }^{11}$ Velleman introduces similar teleological features in his account by making it a criterial feature of agency that one constitutively aim at self-knowledge, where that aiming can be done more or less successfully. ${ }^{12}$ Katsafanas has recently defended a Nietzschian constitutivist account of agency

Korsgaard, Self-Constitution, 160.

Korsgaard, Self-Constitution, ch. 2.

This point is nicely made by Walden, "Laws of Nature, Laws of Freedom, and the Social Construction of Normativity."

Velleman, The Possibility of Practical Reason and "Replies to Discussion on The Possibility of Practical Reason." 
in which the constitutive aims of action are coherence and the will to power. On this view, one can be more or less coherent and thus be a better or worse agent. ${ }^{13}$ Michael Smith has developed his account of idealized agency into a constitutivist explanation of practical normativity that seems best accounted for on a scalar model. On his view, for example, it is constitutive of the ideally rational agent that they have the desire to help and not harm, but in order to be an agent-and thereby be governed by the norms that the ideally rational agent necessarily satisfies-individual agents need not fully have these desires. ${ }^{14}$

Of course, there are worries about these scalar accounts and whether they can provide genuine normative assessments or standards. Clark, for example, considers a variant of Velleman's view on which some amount of autonomy, short of perfect autonomy, is required for action. Clark worries that this move would not fully account for the standard normative assessment for actions because the goal of autonomy up to a threshold cannot serve as a standard of assessment for action. Setiya objects that the constitutive normative requirements on these accounts do not provide sufficient material to fully account for practical norms or their scope. ${ }^{15}$ Though the scalar accounts do not yet amount to responses to these worries, they do make progress over the naïve constitutivist account that falls to Violability concerns. Here, I want to focus on a problem arising precisely from the feature of scalar accounts that allows them to satisfy Violability.

\section{THRESHOLD CONSTITUTIVISM}

Such constitutivists make room for defective kind-members by identifying the metaphysical property essential for kind-hood with some minimal threshold of normative properties, rather than a single bivalent normative property. So, e.g., minimal conformity to the norms of action, rather than perfect conformity, is constitutive of action. This is progress over the naive constitutivist account, which risks identifying the perfect with the real. However, by giving minimal norm satisfaction a criterial role, they maintain an identification of the real with the minimally good. Such views are unsatisfactory because they involve an implicit endorsement of what I call the Threshold Commitment:

Threshold Commitment: For norm-governed kinds, an individual must at 
least partially satisfy the constitutive norms of a kind, or partially meet the constitutive aim of a kind, in order to be a member of that kind. ${ }^{16}$

In other words, norm-governed kinds are those that have kind-membership conditions constituted by minimally having the normative properties that are good-making for that kind. This is supposed to explain why individual kind-members must meet normative standards in a way that does not, in Korsgaard's words, explain it a little too well. Normative violators risk nonexistence, though there are many ways of falling short before you cease being a kind-member. ${ }^{17}$ So, the Threshold Commitment is another commitment to normative satisfaction itself being a constitutive condition on kind-hood, albeit one that permits satisfying those norms to a greater degree with being better qua kind-member. ${ }^{18}$

This commitment is widespread among constitutivists. ${ }^{19}$ Korsgaard, in introducing constitutive standards in the introduction to The Constitution of Agency writes:

Two things are important to notice about standards of this kind. First of all, constitutive standards are at once normative and descriptive. They are descriptive because an object must meet them, or at least aspire to meet them, in order to be what it is. And they are normative because an object

Note that the Threshold Commitment does not simply claim that there are thresholds that determine kind-membership; it takes a stand on the nature of those thresholds: they are determined by normative properties. Importantly, the Threshold Commitment takes a normative difference and attributes to it a metaphysical significance. Nothing in this paper should be taken as an argument against the possibility of understanding important or interesting relationships between normative failures and metaphysical status. Here I am simply highlighting a particular commitment that many constitutivists have to normative goodness itself being criterial or constitutive of kind-membership, and, correlatively, to there being criterial thresholds constituted by normative conditions.

17 It is not essential that there is a scalar norm that serves as the unique criterion for the Threshold Commitment. A similarly workable account might feature a number of binary criteria such that each would make a $K$-member better if it satisfied the criteria but any of which would be sufficient for making an individual $x$ such a $K$-member.

On some readings of Korsgaard, this also leads to an identification of satisfying more $\mathrm{K}$-norms with being more of a $\mathrm{K}$-member and thus with being more evaluable by the constitutive norms of the relevant kind. I think that this is unlikely to be the best version of a Korsgaard-style view, but it is possibly her actual view. For a defense of this interpretation of Korsgaard and an argument that this view faces a related worry, see Silverstein, "Teleology and Normativity."

19 Matthew Silverstein has recently argued that endorsement of something like the Threshold Commitment is a problem for Korsgaard's constitutive account. The problems he identifies differ from mine, and his criticisms are limited to Korsgaard, but we substantially agree on the cause of the problem. See Silverstein, "Teleology and Normativity." 
to which they apply can fail to meet them, at least to some extent, and is subject to criticism if it does not. This double nature finds expression in the fact that we can criticize such objects by saying that they are poor objects of their kind ("That's a poor encyclopedia, it isn't up to date!") or by saying that they are not such objects at all ("That's not an encyclopedia: it's just a compendium of nineteenth-century opinion!"). ${ }^{20}$

Korsgaard holds both that it is a good-making standard of encyclopedias that they are up to date, and that sufficiently out-of-date encyclopedias are not encyclopedias but rather mere compendia of the opinion of a time.

Other constitutivists make similarly clear commitments. Katsafanas writes:

There is a great deal of distance between the standards minimally constitutive of househood and the standards of an excellent house. There is a great deal of distance between a plywood shack in the forest that will dissolve back into the environment in a few years, and a sturdy stone house that will last for centuries. Both of these count as houses, but it seems natural to say that the stone house is a better house. We might describe this by saying that the same standards apply to the stone house and the shack: the standards of househood. But there are better and worse ways of fulfilling these standards. At some point, a structure will have met the standards to a sufficient degree to qualify as a house, but will not have met the standards to a sufficient degree to qualify as an excellent house. ${ }^{21}$

Katsafanas, like Korsgaard, is committed to both the Threshold Commitment and a connection between norms and fundamental evaluative assessment. The normative properties of houses account for both the metaphysical difference between househood and non-househood, and the evaluative difference between merely adequate and excellent houses. These are the dual roles given to normative standards by those we might call "Threshold Constitutivists."

As Korsgaard highlights, one appeal of the Threshold Commitment is its support for some (though, of course, not all) of our linguistic practices involving attributing and denying kind-hood to objects of evaluation. Though we might not identify perfection and reality, sometimes we do talk as if we identify extreme defect and nonbeing. I suspect we are less likely to join Korsgaard in accusing out-of-date encyclopedias of being non-encyclopedias; however, we do seem to make claims like (pointing to the liquid in a mug), "This coffee is so bad, it's not 
even coffee!"22 If meeting a minimum normative standard of coffee were a metaphysical condition on being coffee, this could be a literally true claim about the metaphysical status of the liquid under discussion rather than a metaphorical expression of disapproval. Implausibly, being bad enough at being coffee could constitute (directly and literally) not being coffee. If so, Lynch is wrong about some bad coffee; sometimes having bad enough coffee just is having none at all.

Linguistic appeals aside, according to its proponents the main advantage of understanding threshold normative properties as metaphysically constitutive of kind-membership is the ability to explain the legitimate normativity of those properties and to answer skeptical challenges to their authority. Korsgaard writes that "the only way to establish the authority of any purported normative principle is to establish that it is constitutive of something to which the person whom it governs is committed-something that she either is doing or has to do." ${ }^{23}$ According to Korsgaard, what should make you interested in building a good house is the risk that if you do not do it well enough, you will not end up with a house at all. This move requires something like a threshold; there is some existential (not merely pragmatic) risk of not satisfying kind-norms. In a similar spirit, Katsafanas writes that "a builder must aim at building a good house, if by 'good' [we] mean a house that is at or above the cut-off point for househood." 24 The Threshold Commitment is not an ad hoc or ancillary feature of these constitutivist views. ${ }^{25}$

\section{THE COST OF REDUCED EXPLANATORY UNITY}

Though Threshold Constitutivism makes progress over naïve constitutivism, it comes with serious costs. Normative Constitutivism has ambitions to be an explanatory strategy for norms in general. If there are norm-governed kinds without normative thresholds, then one cost to Threshold Constitutivists is decreased explanatory scope. Indeed, social kinds like Spouse appear to provide

22 This was once said to me by Luca Ferrero, who, years later, refuses to retract the claim or accept it as a figure of speech. It was, indeed, very bad. I maintain it was still clearly coffee.

23 Korsgaard, Self-Constitution, 32.

24 This move worries those suspicious that constitutivism does not require us to care about norms as such, or goodness as such, but only some more minimal standards. For example, see Enoch, "Agency, Shmagency" and "Shmagency Revisited." The objection I am developing here holds even if the Threshold Constitutivist can address Enoch's worries.

25 Some constitutivists appeal less to Threshold-type claims. In section 6, below, I argue that versions of constitutive aim accounts do not obviously avoid the Threshold Commitment. In section 7, I sketch a possible constitutive account that I argue does avoid the Threshold Commitment and is worth further development. 
ready cases of kinds that lack normative thresholds. ${ }^{26}$ Given the importance of explanatory unity, this means that Threshold Constitutivism comes with a cost of reduced explanatory unity.

It is clearly possible for there to be better and worse spouses and for particular spouses to improve or become worse qua spouse. We then are committed to thinking that there are ways of being a better and worse spouse that are generally true of spouses that we track when we make these assessments. The norms of spouses are those standards that would, when satisfied, make a spouse better qua spouse, and these norms are the subject matter of constitutivist explanation. The constitutivist will want to find some constitutive feature of spouses that explains the norms according to which we assess individual spouses as better or worse. ${ }^{27}$ Spouse is, so understood, a goodness-fixing kind, the norms of which come from its constitutive nature. ${ }^{28}$

However, satisfying these norms to some minimal degree does not seem to be a constitutive requirement of being a spouse at all. One does not become a spouse by being a good enough one, and one cannot cease being a spouse merely in virtue of being a bad enough one. The metaphysical conditions on spousehood seem to involve multiply realizable social recognition practices. Different social groups can determine different practices for the social recognition, but at least in contemporary practice, we take legal recognition to be at least partially determinant of becoming a spouse, and recognized removal of legal recognition to be a sufficient (and, along with the death of one's spouse, exhaustive) condition on ceasing to be a spouse.

This is supported by how we view the recent changes in constitutional law in the United States. We recognize these changes to have permitted same-sex couples to become spouses. We do not tend to think that they were already spouses and that the law needed to be changed to recognize this fact. ${ }^{29}$ This indicates that we view legal recognition as a condition on having the social kind Spouse,

Throughout, I use the singular, capitalized noun to pick out the kind, and lowercase uses to pick out instances in the singular or plural. So, here, I consider the kind Spouse, and later I discuss individual conditions on being a spouse and the norms that spouses are assessed according to.

Though it seems pretty clear to me that such an explanation is plausibly in the offing, nothing here turns on there being such an explanation. All we need here is the conclusion that the Threshold Commitment will make this explanation impossible for the kind.

28 See Thomson, Normativity, for discussion of goodness-fixing kinds and an argument supporting this move from judgments of being better and worse qua $\mathrm{K}$ to $\mathrm{K}$ norms.

29 For example, none of the couples in Obergefell reported that they wanted to have the state recognize that they were already married; the fight for gay marriage was the fight to recognize the significance of same-sex partnerships by permitting them to be marriages. 
rather than as conveying a distinct kind-status that one can gain in addition to the social kind. Though legal recognition is just one way that social groups could choose to determine spousal-recognition conditions, it seems that the way one gains the social kind Spouse here is by undergoing certain legally recognized and sanctioned events. ${ }^{30}$

Just as someone does not need to be any good (or even intend to be good) according to the norms of spouses to become one, spouses also cannot lose their spouse-hood in virtue of becoming a bad enough spouse. Divorce and death: those are the ways to cease being a spouse. Divorce is just the term we have for the way in which two spouses dissolve a marriage through social recognition. It is this dissolution of the social recognition, itself multiply realizable, that constitutes loss of kind-membership. ${ }^{31}$ Given the need for the retraction of social recognition (or possibly death), extreme defect would only be existentially risky for very bad spouses if extreme defect was retraction of social recognition. However, defect just is not the sort of thing that could be retraction of social recognition. Extreme spousal badness could be grounds for a marriage to be dissolved, but mistreatment or abandonment it is not itself a divorce. Even if we thought that having the intention to divorce your spouse were a way of being a bad spouse, the intention to divorce is insufficient (and given the possibility of dissolution of marriage by death, unnecessary) to cease being a spouse. The completed divorce, not the intention that begins it, dissolves a marriage. ${ }^{32}$

The role that normative thresholds supposedly play in providing reasons is also missing in the spousal case. Among all the reasons you might take yourself to have for being a good spouse, you would never consider that, in being a bad spouse, you might end up automatically divorced. We take spouses to have the right to determine, for themselves, just how bad a spouse they will tolerate. Surely, some people might have the Lynch coffee attitude toward spouses: having a

30 Even in places where common-law spouses are possible, one does not become a spouse merely by acting as a spouse does; these cases are possible because one way of having social recognition in these places is by recognizing common-law marriages. If acting as a spouse were sufficient to be a spouse, independent of recognition by a larger social body, then many same-sex couples could have been accurately described as having their spousal status recognized, rather than constituted, when they first legally married, but this is not what happened.

31 I am tempted to also say that death is a way to stop being a spouse independently of the dissolution of social recognition, but it seems that in some social groups one can still be a spouse when widowed. It might be that in social groups like ours in which death is a way to cease being a spouse, it is a socially recognized way of loss of kind-membership.

Even in cases like Catholic marriages in which the conditions for successful recognition include certain intentions, like to raise one's children in the church, if it is later demonstrated that these conditions were not met, this does not dissolve the marriage. Such demonstrations (i.e., annulments) establish that a marriage never occurred in the first place. 
very bad spouse might be better than none at all. It seems implausible that such people might end up in a position in which, despite the interests of both to maintain their (very bad) marriage, they find themselves not spouses.

We thus have a kind, Spouse, that is norm governed but whose norms do not constitute threshold conditions on kind-membership. In at least some cases, then, individual persistence conditions do not seem metaphysically tied to normative conditions. Because of cases like this, Threshold Constitutivists are faced with a choice: narrow the scope of constitutivist explanation to exclude the norms of kinds like Spouses, or reject the Threshold Commitment.

The former option should not be taken lightly. One important standard of explanations is how well they unify the various phenomena to be explained and by how well their argumentative patterns can be used to explain a wide variety of phenomena. ${ }^{33}$ Thus, a constitutivist explanation that is able to explain the norms of Spouses is thereby better than one that is unable to do so. Moreover, given that one of the promises of constitutivism is its seeming ability to provide a general explanatory account of the norms of any norm-governed kind by appeal to its constitutive features, constitutivists should be averse to any commitment that restricts the project's explanatory scope.

\section{THE COST OF COUNTERINTUITIVE PERSISTENCE CONDITIONS}

Unlike social kinds like Spouses, physical artifacts make particularly striking examples of cases in which defect seems to lead pretty straightforwardly to destruction. It is not surprising then that they are often used to illustrate the Threshold Commitment. Houses are commonly used to illustrate the metaphysical risk that defect poses. Korsgaard, for instance, uses a discussion of defective houses in one of her clearest discussions of the Threshold Commitment:

On this view, to be an object, and to be teleologically organized, are one and the same thing. Teleological organization is what unifies what would otherwise be a mere heap of matter into a particular object or particular kind.... At the same time, it is the teleological organization or form of the object that supports normative judgments about it. A house with cracks in the walls is less good at keeping the weather out, less good at sheltering, and therefore a less good house. The ancient metaphysical thesis of the identification of the real with the good follows immediately from this conception, for this kind of badness eventually shades off into literal dis-

33 See, e.g., Friedman, "Explanation and Scientific Understanding"; Kitcher, "Explanatory Unification" and "Explanatory Unification and the Causal Structure of the World." 
integration. A house with enough cracks in the walls will crumble, and cease to be a house altogether: it will disintegrate back into a mere heap of boards and plaster and bricks. ${ }^{34}$

In endorsing what she calls the "ancient metaphysical thesis of the identification of the real with the good," Korsgaard identifies being a house with minimal house goodness. It is a particularly compelling example: it is certainly true that the house's very existence is increasingly threatened by mounting normative failure. The case is supposed to provide a clear illustration of the Threshold Commitment because in the case of artifacts loss of kind-membership (or "the real") is a matter of physical destruction. Because badness is supposed to "shade into" physical destruction, being sufficiently bad is a way of becoming non-real, as the Threshold Commitment says.

However, this is a mistake. Though the house case is used to illustrate the Threshold Commitment, this illustration turns on misinterpreting a causal connection as a constitutive one. A house with enough cracks in the walls is very likely to crumble, but it is the crumbling, rather than the badness, that shades into literal disintegration. Considering a case of a house at the brink of extreme defect can help us see why artifacts should not be used to support the Threshold Commitment.

The Very Bad House: A Very Bad House is vacant and has been left to the elements. By time $t_{1}$, it is on the brink of physical collapse. Let us grant that there is some normative threshold for houses: there is at least one way of becoming so bad according to the norms of houses that any additional normative failure would constitute loss of househood. The Very Bad House, by stipulation, sits on the house-side of the threshold at $t_{1}$. If the house were to become any worse, it would pass over the normative threshold and the resulting arrangement of bricks and shingles would not be a house or would be a "house" in name only.

At $t_{2}$ two things happen. First, the Very Bad House fails according to yet another house norm (or norms), which constitutes it passing below the normative threshold. ${ }^{35}$ However, simultaneously at $t_{2}$, a witch on a

Korsgaard, Self-Constitution, 28.

It is not important to the threshold account whether nonbeing requires normative failure according to one or to many norms. The important thing is that the threshold theorist thinks that normative failure alone can make the metaphysical difference. Threshold defenders might claim that the connection between badness and existence is vague, making the threshold vague too. This should not affect the argument. So long as the metaphysical difference is only a matter of normative failure, a case can still be produced by finding some extreme amount of defect that would be sufficient to surpass the vague threshold. For the 
conveniently timed walk notices the house's condition. Fearing the worst, she casts a spell causing a strong wind to blow in just the way necessary to keep the house standing. ${ }^{36}$ Unlike unsupported structures, which would collapse in the house's condition at $t_{2}$, the Very Bad House has been physically preserved.

In order to maintain the identification of the real and the good, the Threshold Constitutivist seems committed to admitting that houses can cease to be real without being physically destroyed. However, it is the connection between physical destruction and reality in the case of artifacts that makes them such compelling examples. To maintain the intuitive force of these cases, the Threshold Constitutivist needs to account for some property that could explain how, contrary to the description in the example, the Very Bad House remains minimally good at $t_{2}$ when the wind prevents it from falling. However, I will show that there are no plausibly good-making properties that will ensure the Very Bad House will remain standing at $t_{2}$.

At $t_{2}$ the Very Bad House gains the property of being held up by a strong wind. ${ }^{37}$ This new property does not seem to be a property that makes a house better qua house. ${ }^{38}$ More plausibly, the Threshold Constitutivist will think that being held up by the wind preserves some other property of the Very Bad House between $t_{1}$ and $t_{2}$ that keeps it from becoming worse. Their task is then to show that there is some property of the Very Bad House that (a) the house has at $t_{1}$, (b) is maintained by the wind at $t_{2}$, and (c) is good-making at $t_{2}$. Moreover, in order to preserve the connection between nonbeing and physical destruction, it must (d) be a property that, if lost, would constitute the Very Bad House's physical destruction.

Three properties might meet these conditions: being standing, stability, and having the ability to shelter. The property most obviously suited to (d) is being standing. Being standing is clearly related to physical persistence. It is also clearly a property that the wind preserves between $t_{1}$ and $t_{2}$. However, it is too closely related to physical persistence for it to be good-making for houses. Because the connection between defect and nonbeing is a physical matter in the case of ar-

case at hand, all that matters is that the difference between the house at $t_{1}$ and $t_{2}$ can be explained in terms of normative satisfaction.

Or if you prefer, a very quick builder on a similar walk erects temporary scaffolding, finishing precisely at $t_{2}$.

The Threshold Constitutivist might also think that the house has the property of being bewitched, but the weather is bewitched, not the house.

38 To see this, consider that for a property $p$ to be a good making property for Ks, it must be that if having $p$ makes $X$ a better $K$, for any other $K, Y$, it must make $Y$ a better $K$. 
tifacts, remaining standing is a minimal condition on being a house at all. But if it were a norm of houses that they were standing, it would be a consequence of something being a house that it satisfied this norm; i.e., it would run afoul of Violability. So, the fact that the Very Bad House remains standing cannot account for it remaining minimally good at $t_{2}{ }^{39}$

Though remaining standing cannot itself be good-making, it could be that, in addition to remaining standing, the wind keeps the Very Bad House stable at $t_{2}$. Unlike remaining standing, stability seems gradable, avoiding an immediate source of conflict with Violability. Even better, stability seems plausibly good-making for houses. However, it is not clear that the house at $t_{2}$ does have a relevantly good-making property of stability.

Stability is a dispositional property whose manifestation response is standing. Though the manifestation response cannot be good-making, the disposition itself seems to be. Problematically, however, stability is an unusual disposition, because its manifestation response is not change but stasis. ${ }^{40}$ Fragility is the disposition, say, to break when struck - that is, to undergo a certain change under certain stimulus conditions. But stability is a disposition to maintain orientation or structural form given environmental changes - that is, to maintain properties under certain stimulus conditions. Given this and the connection between reality and the manifestation response of this disposition, it is harder to account for how it could be a good-making property the Very Bad House has at $t_{2}$.

To see why, consider a distinction made by Vetter, who notes that possessing some dispositions (threshold dispositions) requires having the manifestation response in some proportion of cases, while possessing other dispositions (permissive dispositions) only requires having the manifestation response in a single case. ${ }^{41}$ Breakability is a permissive disposition; in order to be breakable, there need only be one condition in which an object would break. Fragility is a threshold disposition; in order to be fragile, an object must be easily breakable - there must be some sufficiently large number of cases in which it would break. So, we can ask, is stability a threshold disposition, like fragility, or a permissive disposition, like breakability?

One way to easily guarantee that the Very Bad House has dispositional stability maintained between $t_{1}$ and $t_{2}$ is to understand it as a permissive disposition, always had by things that are standing. In keeping the house standing, the wind

39 We might also put the point this way: remaining standing in this case is a binary property that is a criterial condition on kind-membership. It is bound to be ruled out on grounds discussed in section 1 , above.

See Williams, "Static and Dynamic Dispositions."

Vetter, "Dispositions without Conditionals," 144. 
preserves the permissive disposition of stability. However, given the connection between physical persistence and reality, all houses are standing and thus all houses are dispositionally stable. So permissive stability runs afoul of Violability like being standing does.

On the other hand, stability could be a threshold disposition. Then there will be some conditions in which objects have the manifestation response of stability (remain standing) without having the disposition (stability). This would allow there to be non-stable houses, which resolves the problem with Violability. Unfortunately, understanding the relevant sense of stability as threshold stability undermines the plausibility that stability is preserved by the wind at $t_{2}$. If there are any cases in which a standing house does not have the threshold disposition of stability, the Very Bad House at $t_{2}$ would be one. In fact, the example of the Very Bad House is designed so that it describes an instance of a standing thing that lacks the threshold disposition of stability. Either way of understanding dispositional stability seems unable to serve the Threshold Constitutivist's purposes of being a property that is both good-making and preserved by the wind between $t_{1}$ and $t_{2}$.

The final potentially preserved property of the house, the ability to shelter, does no better than remaining standing or stability. Whatever this sheltering ability is, if it is to be a good-making property of houses, it cannot be a feature had by any standing house. So there must be some ways of preserving the physical structure of a house while not preserving the good-making ability to shelter. That, by hypothesis, is what is being done by the wind at $t_{2}$. Of course, there might some ability to shelter that all non-destroyed houses possess, but this cannot be a good-making ability. The issue here, as with the other properties, is that defect cannot shade into destruction by shading into physical destruction. If Violability is true and being non-destroyed is a requirement on the real, then no property that is had by all non-destroyed $K$-members can be good-making for Ks.

The Threshold Constitutivist must instead accept that, despite the fact that it is not physically destroyed, the Very Bad House is not a house at $t_{2}$. There could be some explanation of the kind House that would make this counterintuitive result more palatable. Regardless of whether such an explanation can be provided, the issue remains that the appeal to physical artifacts to support the identification of the real and the good is misguided. Appeals to cases of physical artifacts, like houses, exploit the fact that defect can lead to physical destruction in a mistaken attempt to illustrate that defect can itself constitute nonbeing. But defect does not entail physical destruction, so if defect does entail nonbeing, rather than being the most plausible illustrations of the Threshold Commitment, 
physical artifacts actually serve as rather counterintuitive cases for proponents to explain.

\section{THE COST OF NORMATIVE ANEMIA}

In the case of Houses, Threshold Constitutivists hoped that the metaphysical significance of destruction and the relation of defect and destruction could make the Threshold Commitment plausible. But we have seen that preserving the Threshold Commitment requires normative failure itself, and not the destruction that it often leads to, to make the metaphysical difference. In the case of Houses, this comes at the cost of accommodating some counterintuitive results. In the case of Spouses, it comes at the cost of restricting the explanatory scope of Threshold Constitutivists' explanatory project. But it comes with another cost: giving norms this metaphysical significance undermines their other normative roles.

For the Threshold Constitutivist, normative standards are not merely the basis for normative evaluation; they also determine the criterial conditions for kind-membership. As Korsgaard puts it, an "object to which they apply can fail to meet them, at least to some extent, and is subject to criticism if it does not." ${ }^{22}$ This distinguishes threshold constitutivism from other constitutivist accounts that locate the metaphysical criteria of kind-membership elsewhere. The Threshold Constitutivist thereby holds that there are some events that constitute both a violation of a $K$-norm by some $K$-member, $x$, and the loss of $K$-membership by $x$, and the violation constitutes rather than causes or precipitates the kind-loss.

Constitutivists generally share a commitment to a fundamental role for kind-determined norms in evaluation. According to constitutivists, constitutively understood norms come from the nature of the thing they govern. ${ }^{43}$ They thus yield a special sort of internal evaluation that is distinguished from evaluation according to some external purpose. Because of this, constitutively understood norms generate kind-dependent assessments that permit us to, e.g., distinguish the standards that make something good or bad qua house from those that make it good or bad qua thing in the neighborhood, status symbol, or instance of modern architecture. ${ }^{44}$ Constitutively understood norms are thus kind-specific

\section{Korsgaard, The Constitution of Agency, 8.}

For a discussion of goodness-fixing kinds and kind-defect/virtue, see Thomson, Normativity.

For example, Korsgaard distinguishes between being a good or bad house in what she calls "the strict sense" and being a house that happens to be a good or bad thing "for some external reason." The first strict sense is determined by "constitutive standards," "standards that apply to a thing simply in virtue of its being the kind of thing that it is." What Korsgaard calls “constitutive standards," I am here calling norms. Korsgaard, Self-Constitution, 28. 
norms that are tied to a particular and important kind of normative status: being good or bad qua kind-member. There are two aspects of this evaluative role of norms: first, that defects and virtues are kind-dependent and second, that norm violation and satisfaction by kind-members have kind-relative evaluative consequences.

A noteworthy consequence of the Threshold Commitment is that norm violation of kind-members does not always lead to kind-relative evaluative consequences. The Threshold Constitutivist denies that for any $K$-member, $x$, governed by a $K$-norm, $N, x$ would be defective if $x$ violated $N$. They must, because on their account there will be some $x$ 's that, when they violate $N$, do not become a worse $K$, but become a non- $K$. Of course, constitutive norms pick out good- and bad-making features of kind-members, given the nature of the kind in question. ${ }^{45}$ If you satisfy a $K$-norm and you are a $K$-member, then the property you have that constitutes your satisfaction of the $K$-norm is good-making. But more than this, according to constitutivists, $K$-norms have particular force for $K$-members that they lack for non- $K$-members. This is how Korsgaard claims constitutivists can answer skeptical challenges with ease. ${ }^{46}$ When asking why we ought to care about the norms that govern us, the fact that we are at risk of falling apart if we become bad enough is supposed to show that those norms have authoritative force for us; we cannot help but care about them.

But the general normative force of norms cannot turn on the kind-members in question caring about the risk of nonexistence. Norms cannot, in general, have force for kind-members they govern because the kind-members care about something else that satisfying the norms is essential for (how, for example, would that account for the force of house norms; houses care for nothing). Norms must have force because of their connection to their kinds, and that is what the constitutive connection is supposed to provide. Somehow the fact that sufficient defect is existentially risky is supposed to give norms their force. On the contrary, however, this existential risk seems to undermine the account of their force. If a particular house being a house turns on its being waterproof, if it were at risk of becoming a non-house by becoming leakier, it is hard to see how the demand to be waterproof itself could then have any normative force. The demand loses its normative bite as soon as it is violated.

45 See, for example, Korsgaard, Self-Constitution, 33, in which she argues that we need constitutive standards because of the importance of the normative concept of defect.

"Because it does not make sense to ask whether a house should serve as a shelter, it also does not make sense to ask if the corners should be sealed and the roof should be waterproof and tight ... there is no further room for doubting that the constitutive standard has normative force. For if you fall too far short of the constitutive standard, what you produce will simply not be a house." Korsgaard, The Constitution of Agency, 29. 
At these thresholds, we can see the weakness, the anemia, of the metaphysical account. Taking minimal normative satisfaction to be criterial for kind-membership makes that kind-membership unsuited to explain the force of those norms. The force of norms for some individual cannot be explained by the fact that they are currently satisfying some subset of them. At the limit case, this would mean that a norm has force because it is being satisfied. This account does not give internal standards any greater authority than the external standards that constitutivists want to distinguish constitutively understood standards from. Taking normative standards to be both criterial and normative undermines the explanation of their normative force. Not only does the Threshold Commitment come with explanatory costs related to scope and intuitive persistence conditions, it also seems to block central explanations of features like normative force.

\section{CONSTITUTIVE AIMS DO NOT AVOID THRESHOLDS}

Above, I argued that the Threshold Commitment is a flawed account of a constraint on norm-governed kind-membership. Constitutivists should thus recognize a need for reconsideration of the metaphysical basis of constitutivist explanations. ${ }^{47}$ However, though many constitutivists like Katsafanas and Korsgaard explicitly endorse something like the Threshold Commitment and it seems implied in other accounts, some constitutivist accounts that explain constitutive features in terms of constitutive aims might already seem to have resources to avoid the Threshold Commitment. To take a brief example, if truth is the constitutive aim of belief, this aim might be used to explain the norms governing beliefs, though no particular belief must be even minimally true to account for it having the constitutive aim. Because having a constitutive aim is neither good-making nor scalar, constitutive-aim accounts might already avoid the Threshold Commitment, making further development unnecessary. Despite this appeal, constitutive aims are no more suited than other constitutive properties to avoid the Threshold Commitment, or so I argue in this section.

Constitutive aims will be suitable for this purpose if the account of how kind-members have the aim both avoids requiring minimal kind-goodness and also provides the metaphysical grounds for normative explanations. I first consider whether it is possible to give an account of aiming that any action (or-more broadly — any norm-governed kind) could be understood as having. Then I discuss two views that provide explanations of how kind-members have constitutive aims: Velleman's view that self-knowledge is the constitutive aim of action and Wedgwood's view that truth is the constitutive aim of belief. Nei-

Thanks to an anonymous referee for highlighting the need for the discussion in this section. 
ther account, I argue, provides a metaphysical account that avoids the Threshold Commitment while providing the resources to ground normative explanations. I conclude that these failures show that having a constitutive aim is not going to provide a satisfactory way to avoid the Threshold Commitment.

Let us start with a commonly discussed example: one might hold that it is constitutive of playing chess to have the aim of checkmating your opponent, though one of course need not minimally succeed at checkmating an opponent, whatever that might be, or be minimally good according to the rules of chess. A constitutivist account of the norms of chess that appealed to this aim would need an explanation of what metaphysical property (or properties) constitutes having this aim. If such an explanation could be given without identifying having the aim with minimal normative properties, and this explanation could then be used to explain chess norms, it would be a successful constitutivist account that avoided thresholds. ${ }^{48}$ I think constitutive aims are unlikely to be accounted for by properties that could play this role for constitutivists. ${ }^{49}$

In the case of chess playing, the most straightforward way to account for having its constitutive aim might be by appeal to the intentions of the player. Whatever metaphysical account we might give of intending to checkmate might be used to account for having the aim of checkmating. Putting aside the fact that the metaphysics of intentions are controversial, accounting for constitutive aims by appeal to intentions is unlikely to work for constitutivist accounts of the norms of action generally because it is does not generalize to the central case of agency. If the constitutive aim of agency requires having an intention, which only agents can have, this introduces problematic bootstrapping: the source of the constitutive feature is the very thing constituted by that feature. The ability to have the constitutive aim seems to presuppose already having it. ${ }^{50}$

Velleman recognizes this bootstrapping problem and attempts to avoid it by locating the source of the constitutive aim of action subagentially. In what follows, I explain how Velleman's account of the constitutive aim of action does implicitly rely on the Threshold Commitment. On his account, the constitutive aim of action is self-knowledge, but an action gets this aim not from an agential intention, but from the agent's subagential desire to know what she is doing. The

Importantly, I think there can be successful threshold-free constitutivist accounts. My goal here is only to show that constitutive-aim accounts are not the place to look for them.

49 Chess is perhaps not as good a case as constitutivists sometimes assume. It seems unlikely that we will be able to explain the norms of chess by appeal to the aim of chess, regardless of whether we can identify a property that constitutes having the aim of checkmating; see Dreier, "When Do Goals Explain the Norms that Advance Them?"

See, for instance, Arruda, "Constitutivism and the Self-Reflection Requirement." 
intellect has the aim of knowledge, and a special case of that aim is self-knowledge. Importantly, in acting, we have access to non-observational self-knowledge of what we are up to. What distinguishes action from mere behavior, then, is that in acting we make ourselves the authors of our actions. In order to do this, the intellect takes the self as a subject, and so the constitutive aim of action is "the aim of our intellects as focused on ourselves, the aim to which practical knowledge is the obvious shortcut, the aim of knowing what we are doing." 51 To explain this, Velleman considers a case of mere behavior: Freud's account of knocking over an inkstand and realizing, after the fact, that he knocked it off his desk because he desired a new one, and, believing his sister would buy him one as a present, he wished to make room for it. Velleman writes that in order for the mere behavior to have counted as an action Freud "would need to have been actuated not only by the desire and belief mentioned in the story but also by the story itself, serving as his grasp of what he was doing —or, in other words, as his rationale." ${ }^{2}$ So, roughly: the behavior lacked the constitutive aim of action because the behavior was not motivated by a rationale, something that would have provided practical knowledge when acted on.

This role for the rationale introduces thresholds into the account of how subagential desires constitute aims. To constitute action, the desire cannot be merely lurking subconsciously; it has to manifest itself in the sort of grasp we have on what we are up to when we act. In order to act, Velleman believes an agent "would need, first, to have been inhibited from acting on his desire and belief until he knew what he was up to; and then guided to act on them once he had adopted this story. He would then have acted autonomously because he would have acted for a reason, having been actuated in part by a rationale." ${ }^{53}$ So, it is essential for action, on Velleman's constitutive-aiming account, that one must first know what one is up to (or, perhaps, what one will be up to), and then, as behavior is guided by that account as a rationale, one thereby acts for reasons provided by that rationale. The reasons that one has to do something are "considerations in light of which, in doing it, the subject would know what he was doing." ${ }^{54}$ Behavior thus constitutes action when that behavior is guided by reasons, understood as considerations that provide self-knowledge.

But rationales-explanations of what we are up to-can be better or worse at providing self-knowledge. The less self-knowledge they provide, the worse they are as rationales. As Velleman writes, "when an agent selects rationales that

51 Velleman, "Précis of The Possibility of Practical Reason," 236.

52 Velleman, The Possibility of Practical Reason, 29.

53 Velleman, The Possibility of Practical Reason, 8.

54 Velleman, The Possibility of Practical Reason, 26. 
are incongruous with who they are, they ... might have wondered 'what am I doing?' That is, they might have been puzzled as to how a person like them, with a makeup like theirs, would come to act on such motives; and so they wouldn't really or fully have known what they were up to." ${ }^{55}$ So not all rationales help us accomplish our aim of self-knowledge equally well. Still, on Velleman's view, in order to count as having the constitutive aim of self-knowledge, you already have to partially know what you are up to, i.e., you have to already have some self-knowledge that permits you to know what you are doing. Thus, for Velleman, having a constitutive aim requires minimally satisfying that aim. So, constitutive aiming, at least on Velleman's view, does not avoid the Threshold Commitment at all.

Aims relying on agent intentions do not seem suited to the constitutivist explanatory project, and Velleman's constitutive account relying on subagential aims involves a commitment to Thresholds. One further way we might understand constitutive aims is suggested by discussions of the aims of mental states. For example, many philosophers endorse claims of the form "the constitutive aim of belief is truth," or "belief aims at truth." But these claims are not taken to be in conflict with the possibility of false belief, and they do not seem to think that beliefs have this aim because believers intentionally aim at truth. Perhaps, then, these accounts will be constitutive-aim accounts that already avoid the Threshold Commitment.

Ralph Wedgwood is one prominent defender of the claim that truth is the constitutive aim of belief. Wedgwood explains that when we say belief has the constitutive aim of truth we are not attributing some metaphysical property to all beliefs that accounts for this aim; rather, he endorses a view he calls Normativism, according to which belief is the attitude constituted by having truth as its correctness condition. ${ }^{56}$ Similarly we might think that chess has the aim of checkmate in the sense that chess is the game constituted by having checkmate as its success condition. Just as you can actively attempt to believe false things, you can play chess without caring about checkmate or actively throw a game. Maybe you could also act without self-constituting or having self-knowledge. ${ }^{57}$ So, according to Normativism, aims are constitutive of some kind when individ-

Velleman, The Possibility of Practical Reason, 29.

56 See especially Wedgwood, The Nature of Normativity.

57 This is also, plausibly, a more charitable understanding of attributions of constitutive aims, because aiming in the literal sense requires knowing beforehand what you are aiming to get, but believers do not first determine what is true and then attempt to believe it, in the way that archers first locate a target and then try to hit it. See Dreier, "When Do Goals Explain the Norms that Advance Them?" 159-60, for this point. 
uals are members of that kind in virtue of having that aim as their correctness condition.

Normativism explains what it is for an aim to be constitutive of some kind, but it explains kinds by shared norm-assessability (or shared-correctness conditions), not by shared properties that are used to explain their shared norms. So, Normativism does not require any minimal normative satisfaction for constitutive aims and thus avoids the Threshold Commitment. However, it does this by not undertaking the kind of constitutivist explanation we started by motivating: it does not seek to explain the normative features of kinds by appeal to what is constitutive of kind-membership. Instead, it explains what is constitutive of kind-membership by appeal to the correctness conditions shared by kind-members. I do not think this explanatory work is ruled out for Normativists; the view might be paired with a metaphysical account of why kind-members had these correctness conditions. But, in this case, the constitutivist explanation of the normative features would not be in terms of constitutive aims.

So, constitutive aims do not seem to help current constitutivists avoid the Threshold Commitment. Constitutive aims that require intentional aimings run into bootstrapping worries, which led Velleman to explain them in terms of subagential desires. These are not threshold free, however, as we saw that having behavior rationalized by desire in the way needed for it to have the constitutive aim of self-knowledge required minimal self-knowledge. Alternatively, accounts that explain constitutive aims as correctness conditions avoid normative thresholds, but do not use aims to provide the sort of constitutive explanation under consideration. If the Threshold Commitment is a problem for constitutivism, as I argued above, constitutive aims are not a solution for constitutivists.

\section{CONSTITUTIVISM WITHOUT NORMATIVE THRESHOLDS}

Though many constitutivists endorse and are committed to the Threshold Commitment, even Threshold Constitutivists do not take it to be an essential feature of constitutivist accounts. ${ }^{58}$ The Threshold Commitment is only one account of how norms can be constitutively explained.

58 Some constitutivists have a very narrow view of constitutivism, according to which the only views that count as constitutivist are those that take there to be constitutive aims that generate norms. I suspect that Katsafanas thinks this, given the set-up of his book, in which he classifies both Humeans and Aristotelians who appeal to the nature of individuals to explain their goodness as non-constitutivists. Both Judith Thomson and Michael Smith, constitutivists on my account (and Smith's), are classified by Katsafanas as non-constitutivists. Not all constitutivists are so restrictive, of course. This restriction is fine; it might be that on the narrow use of the term we ought to reject constitutivism on the basis of the arguments 
There are a few options open to constitutivists for how norms could be explained in terms of what is constitutive of kind-membership other than making those norms or properties that satisfied them constitutive. We might identify other features as determining constitutive forms or functions (or even aims). Though Korsgaard identifies minimal goodness with form, she also sometimes writes as though performing a function is necessary for having that constitutive function. At times she seems to endorse what we might call a "function-performance" view. For instance, she claims that artifacts must be performing their characteristic activity to count as an artifact. Memorably, she writes that a thing we call a vacuum cleaner is really just a heap that "when properly incorporated by you, makes you into a vacuum cleaner." ${ }^{59}$ Not only is your vacuum cleaner not really a vacuum cleaner when in the closet, but when you vacuum the floor with your heap non-vacuum you become a vacuum cleaner instead of it.

The Threshold Constitutivist requires that the very same properties that make one a good $\mathrm{K}$-member are minimally required to be a $\mathrm{K}$-member at all. In contrast, a function-performance view holds that minimal performance of the characteristic function of $K s$ is required for $K$-membership. If by "minimal performance" we mean "possession of the properties that permit minimal performance," or if we take performing a function to be good-making, then this is a threshold view, but I take it that it is not always so meant. It can also mean that something only has a functional nature when it actually is performing that function, like the vacuum cleaner is only actually a vacuum cleaner when it is vacuuming. If performing the function of vacuuming is what it is to be a vacuum, and you think that the user of the machine rather than the machine is performing the function, you might be tempted, with Korsgaard, to call the human user, rather than the machine, the vacuum. Distinguishing normative satisfaction from functional performance allows us to see two ways we might identify constitutive conditions of kind-membership.

Unfortunately, function-performance views are not going to help the constitutivist, because they mis-account for kind-membership and norm-application. ${ }^{60}$ Pace Korsgaard, I am not a vacuum, as evidenced by the fact that I am

of this paper. At least here, I am using the term in a broader sense. See Katsafanas, Agency and the Foundation of Ethics, 30-34. For constitutivists self-identifying outside of the narrow use, see, e.g., Schafer, "Realism and Constructivism in Kantian Metaethics (1)"; and Smith, "A Constitutivist Theory of Reasons." This identification of constitutive aim accounts with constitutivism is also implicit in some literature critical of constitutivism; see, e.g., Enoch, "Agency, Shmagency."

Korsgaard, Self-Constitution, 37 .

60 For further arguments to this effect, see Lindeman, "Etiological Functions for Constitutivists." 
not assessable according to the norms of vacuums. What the Korsgaard-esque function-performance view calls a heap is properly speaking my vacuum cleaner-and I suspect you and the store that sold it to me agree. Things that are not performing their functions are still members of functionally understood kinds. Additionally, making anything that serves a function a member of a functional kind (as Korsgaard implies by calling me the vacuum cleaner when I use it) risks erasing the distinction between being badly suited to perform a function and being defective. That a piece of aluminum siding is used to saw down a sapling does not make it a saw, and that it is poorly suited to the task does not make it defective. For constitutivists, kind-membership conditions just cannot involve actually performing a function. Constitutivists thus need another account of the constitutive features of kind-membership that can be used to explain norms.

In closing, I suggest that constitutivists should turn to proper functions to provide this account. ${ }^{61}$ In the philosophy of biology, a proper function is the kind of function that something is taken to have non-accidentally, as a feature of what that thing is. ${ }^{62}$ The question, of course, is how proper functions are constitutive of kind-membership or, put another way, what it is in virtue of which any individual has a proper function. There are several requirements on such an account: it must allow Violability by not entailing that any particular normative standard is satisfied, and also not require minimal normative goodness. It must allow for stable kind-membership and for explanations of internal normative standards as well as kind-relative defect and virtue.

Etiological accounts of proper function-those that appeal to the history of individuals and kinds to account for function-are taken to have made teleology safe for naturalists in the sciences by linking functions to evolutionarily determined kinds. ${ }^{63}$ Consider the following quote from Millikan as she explains

61 Proper functions are sometimes contrasted with what are known as systems functions, those that give an account of function of some $\mathrm{x}$ relative to the causal contribution $\mathrm{x}$ plays to the broader capacity of a system in which $\mathrm{x}$ can be understood as being a part. See Cummins, "Functional Analysis," for discussions of systems functions; see Allen, Bekoff, and Lauder, Nature's Purposes, for an overview of this distinction.

62 Millikan stresses that her coinage of "proper" is meant to mirror its etymological ancestor, the Latin proprius, meaning "one's own"; see Millikan, "Biofunctions," 116.

63 Though I do not address alternative accounts of function in this chapter, for a nice overview of the differences between etiological and propensity accounts of function, see Mitchell, "Dispositions or Etiologies?" For presentations and criticisms of the propensity view of functions, according to which the function of an individual or trait depends on how it would fare under selection in some specific environment, see, e.g., Bigelow and Pargetter, "Functions." 
how the etiological proper function of pumping blood accounts for what it is to be a heart:

That a heart is a heart certainly has something to do with pumping blood. But what kind of connection with pumping blood must a heart have? Some hearts are diseased and some are malformed in such a way that they are unable to pump blood. Other devices, such as water pumps, are perfectly capable of pumping blood, yet these are not hearts.... It is not then the actual constitution, powers, or dispositions of a thing that make it a member of a certain biological category. My claim will be that it is the "proper function" of a thing that puts it in a biological category, and this has to do not with its powers, but with its history. ${ }^{64}$

In addition to threshold accounts and function-performance accounts, the constitutivist also has available to her etiological accounts. The account of the history or creation of an individual could explain what it is to have a constitutive function. Having an etiological proper function neither entails that the individual is any good at performing the function nor that they actually perform the function, and so it is not a threshold or a function-performance view. It could, however, account for kind-membership and normative standards governing kind-members. Moreover, etiological accounts need not restrict selection accounts to evolutionary selection. ${ }^{65}$ For example, in the cases of both House and Spouse, histories of individuals are relevant to their kind-membership. In determining whether a person is a spouse, you look to that person's history. Spouses have their kind-status because of historically determinant events: marriages or similar social-recognition events. Houses are given the forms they have by builders who select those forms because of their connection to performing the function of sheltering people in ways suited to primary residences. Houses are the things they are (i.e., structures for primary residence) because of their forms being selected and designed for that purpose. In both cases, we see the historical accounts of individual kind-members as simultaneously explaining their functions and their kind-membership.

The task of fully developing and defending a specific account of proper functions congenial to constitutivists is beyond the scope of this paper, but the

64 Millikan, "In Defense of Proper Functions," 85.

65 In fact, even in biology proper function accounts should not limited to evolutionary selection. See Garson, "Function, Selection, and Construction in the Brain," for a fascinating discussion of the need for non-evolutionary differential-retention accounts to account for proper functions of neural structures, allowing for novel functions unaccountable for on an evolutionary scale, like the function of facilitating Tetris play. 
substantive lessons here should be heartening to those interested in developing constitutive explanations of norms as well as those who are interested in seeing why current constitutive accounts are unsatisfactory. Specifically, norms cannot play the metaphysical role of criteria for kind-membership that Threshold Constitutivists have given them. Constitutivists who give such a criterial role to norm satisfaction must restrict the scope of their constitutive explanations, are pushed to accept implausible permanence conditions for artifacts, and have restricted evaluative consequences of normative failure that block explanations of normative force.

Rather than this being a blow to the constitutivist project, this result should instead encourage constitutivists to look elsewhere for an account of the constitutivist features of good-making kinds with which to explain their norms. I briefly sketched a promising alternative on which functional kind-membership is based in historical facts. Etiological proper functions are available to constitutivists seeking an account of the constitutive features of good-making kinds from which they can explain norms. Clearly there is work to be done to show that an etiological account of proper function could be given for the kinds of interest to constitutivists in the practical and theoretical domains. Nonetheless, given the dim prospects of the alternatives and the general appeal of constitutivism, constitutivists should welcome the development of a constitutivist account based on etiological proper functions. ${ }^{66}$

Saint Louis University kathryn.lindeman@slu.edu

\section{REFERENCES}

Allen, Colin, Marc Bekoff, and George V. Lauder, eds. Nature's Purposes: Analyses of Function and Design in Biology. Cambridge, MA: MIT University Press, 1998. Arruda, Caroline T. "Constitutivism and the Self-Reflection Requirement." Philosophia 44, no. 4 (December 2016): 1165-83.

66 This paper has benefitted substantially from discussions and helpful feedback from many, many people. Special thanks are due to Sarah Buss, Eric Brown, Bob Brandom, John Brunero, Lindsay Crawford, Jamie Dreier, Julia Driver, Meghan Page, Luca Ferrero, Guy Fletcher, Kim Frost, Charlie Kurth, Eliot Michaelson, Claire Morrissey, Tyke Nunez, Hille Paakunainen, Michael Ridge, Connie Rosati, Lizzie Schecter, Karl Schafer, Mark Schroeder, Tim Schroeder, Kieran Setiya, Daniel Singer, Paulina Sliwa, Matthew Smith, Michael Smith, Julia Staffel, Daniel Star, Brian Talbot, Michael Thompson, Katia Vavova, Eric Wiland, an audience at the Midsummer Philosophy Workshop, and several very helpful referees. 
Barandalla, Ana, and Michael Ridge. "Function and Self-Constitution." Analysis 71, no. 2 (April 2011): 364-80.

Bigelow, John, and Robert Pargetter. "Functions." Journal of Philosophy 84, no. 4 (April 1987): 181-96.

Clark, Philip. "Velleman's Autonomism." Ethics 111, no. 3 (April 2001): 580-93.

Cummins, Robert C. "Functional Analysis." Journal of Philosophy 72, no. 20 (November 1975): 741-65.

Dreier, James. "When Do Goals Explain the Norms that Advance Them?” In Oxford Studies in Metaethics, vol. 5, edited by Russ Shafer-Landau, 153-74. Oxford: Oxford University Press, 2010.

Enoch, David. "Agency, Shmagency: Why Normativity Won't Come from What Is Constitutive of Agency." Philosophical Review 115, no. 2 (April 2006): 169-98.

- "Shmagency Revisited." In New Waves in Metaethics, edited by Michael Brady, 208-33. Houndmills, uk: Palgrave Macmillan, 2011.

Friedman, Michael. "Explanation and Scientific Understanding." Journal of Philosophy 71, no. 1 (January 1974): 5-19.

Garson, Justin. "Function, Selection, and Construction in the Brain." Synthese 189, no. 3 (December 2012): 451-81.

Katsafanas, Paul. Agency and the Foundations of Ethics: Nietzschean Constitutivism. Oxford: Oxford University Press, 2013.

Kitcher, Philip. "Explanatory Unification." Philosophy of Science 48, no. 4 (December 1981): 507-31.

- "Explanatory Unification and the Causal Structure of the World." Minnesota Studies in the Philosophy of Science 13 (1989): 410-505.

Korsgaard, Christine M. The Constitution of Agency. Oxford: Oxford University Press, 2008.

- Self-Constitution: Agency, Identity, and Integrity. Oxford: Oxford University Press, 2009.

Lavin, Douglas. "Practical Reason and the Possibility of Error." Ethics 114, no. 3 (April 2004): 424-57.

Lindeman, Kathryn. "An Explanation of Constitutivist Normativity." Unpublished manuscript.

—. "Etiological Functions for Constitutivists." Unpublished manuscript.

Millikan, Ruth Garrett. “Biofunctions: Two Paradigms." In Functions: New Essays in the Philosophy of Psychology and Biology, edited by André Ariew, Robert Cummins, and Mark Perlman, 113-43. Oxford: Oxford University Press, 2002. . "In Defense of Proper Functions." In White Queen Psychology and Other Essays for Alice, 13-29. Cambridge, MA: MIT University Press, 1993. 
Mitchell, Sandra D. "Dispositions or Etiologies? A Comment on Bigelow and Pargetter.” Journal of Philosophy 90, no. 5 (May 1993): 249-59.

Railton, Peter. "On the Hypothetical and Non-Hypothetical in Reasoning about Belief and Action." In Ethics and Practical Reason, edited by Garrett Cullity and Berys Gaut, 53-79. Oxford: Clarendon Press, 1997.

Rosati, Connie S. "Agents and 'Shmagents.” In Oxford Studies in Metaethics, vol. 11, edited by Russ Shafer-Landau, 182-213. Oxford: Oxford University Press, 2016. Schafer, Karl. "Realism and Constructivism in Kantian Metaethics (1): Realism and Constructivism in a Kantian Context." Philosophy Compass 10, no. 10 (October 2015): 690-701.

Setiya, Kieran. "Akrasia and the Constitution of Agency." In Practical Knowledge: Selected Essays, 253-71. Oxford: Oxford University Press, 2016.

—. "Explaining Action." Philosophical Review 112, no. 3 (2003): 339-93. 2007.

Silverstein, Matthew. “The Shmagency Question.” Philosophical Studies 172, no. 5 (May 2015): 1127-42.

- "Teleology and Normativity." In Oxford Studies in Metaethics, vol. 11, edited by Russ Shafer Landau, 214-40. Oxford: Oxford University Press, 2016. Smith, Michael. "A Constitutivist Theory of Reasons: Its Promise and Parts." Law, Ethics, and Philosophy 1 (2013): 9-30.

Thomson, Judith Jarvis. Normativity. Chicago: Open Court Press, 2008.

Tiffany, Evan. "Why Be an Agent?" Australasian Journal of Philosophy 90, no. 2 (June 2012): 223-33.

Velleman, J. David. The Possibility of Practical Reason. Oxford: Oxford University Press, 2000.

- "Précis of The Possibility of Practical Reason." Philosophical Studies 121, no. 3 (December 2004): 225-38.

- "Replies to Discussion on The Possibility of Practical Reason." Philosophical Studies 121, no. 3 (December 2004): 277-98.

Vetter, Barbara. "Dispositions without Conditionals." Mind 123, no. 489 (January 2014): 129-56.

Walden, Kenneth. "Laws of Nature, Laws of Freedom, and the Social Construction of Normativity." In Oxford Studies in Metaethics, vol. 7, edited by Russ Shafer-Landau, 37-79. Oxford: Oxford University Press, 2012.

Wedgwood, Ralph. The Nature of Normativity. Oxford: Oxford University Press, 2007.

Williams, Neil E. "Static and Dynamic Dispositions." Synthese 146, no. 3 (September 2005): 303-24. 